\title{
PAPARAN ABU VULKANIK LETUSAN GUNUNG AGUNG DENGAN KEJADIAN ISPA
}

\author{
I Gusti Ayu Mirah Dewi Sawitri, I Made Dwie Pradnya Susila*, Si Putu Agung Ayu Pertiwi Dewi \\ STIKES Bina Usada Bali \\ e-mail: dwiepradnya@gmail.com*
}

\begin{abstract}
Volcanic ash occurs due to volcanic eruptions that can cause adverse health effects if inhaled. One of which is can cause respiratory problems in the form of respiratory tract irritation, increased phlegm secretion, irritation and inflammation of the throat, dry cough, chest pain, and difficulty breathing. This aimed at determining the correlation between volcanic ash exposure and ARI accident at Public Health Center Rendang Karangasem District Health Center. This study used a correlational research design with the approach used is crosssectional. The sample in this study was 43 people affected by ARI in September 2017 in the area of Puskesmas Rendang Karangasem. Data analysis was using the Mann-Whitney test. The results of this study showed that no significant correlation from this study based on the Mann Whitney test value of 832.5 and the value of $p=0.138$ $(P>0.05)$, meaning at alpha 5\%. It is expected that people who suffer from ARI disease to use masks so as not to aggravate the condition of illness due to ARI and the health center to always provide counseling about healthy lifestyles and avoid ARI.
\end{abstract}

Keywords: volcanic ash, volcanic eruption, ARI

\begin{abstract}
ABSTRAK
Abu vulkanik terjadi akibat letusan gunung yang dapat menimbulkan dampak yang merugikan kesehatan jika terhirup. Salah satunya dapat mengakibatkan gangguan pernafasan berupa iritasi saluran pernafasan sekresi dahak meningkat, iritasi dan radang pada tenggorokan, batuk kering, dada sakit, dan kesulitan bernapas. Adapun tujuan dari penelitian ini adalah untuk mengetahui Hubungan Paparan Abu Vulkanik Dengan Kejadian ISPA Di Puskesmas Kecamatan Rendang Karangasem. Penelitian ini menggunakan desain penelitian korelasional dengan pendekatan yang digunakan yaitu cross-sectional. Sampel dalam penelitian ini adalah masyarakat yang terkena penyakit ISPA pada bulan September 2017 di wilayah Puskesmas Kecamatan Rendang Karangasem sebanyak 43 orang. Data analisis yang menggunakan uji Mann-Whitney. Hasil penelitian ini menunjukan tidak ada hubungan yang signifikan dari penelitian ini dengan berdasarkan nilai uji Mann Whitney sebesar 832,5 dan nilai $\mathrm{p}=0,138(\mathrm{P}>0,05)$, berarti pada alpha 5\%. Diharapkan bagi masyarakat yang mengalami penyakit ISPA agar menggunakan masker supaya tidak memperparah kondisi sakit akibat terjadinya ISPA sertapihak Puskesmas agar selalu memberikan penyuluhan tentang pola hidup sehat dan terhindar dari penyakit ISPA.
\end{abstract}

Kata kunci: abu vulkanik, gunung meletus, ISPA

\section{PENDAHULUAN}

Letusan gunung merupakan peristiwa yang terjadi akibat endapan magma didalam perut bumi yang didorong keluar oleh gas yang bertekanan tinggi. Letusan gunung ini merupakan salah satu bencana alam yang sangat merugikan bagi masyarakat. Ketika meletus, letusan gunungmengeluarkan partikelpartikel yang berbahaya diantaranya gas beracun, lahar panas, awan panas, abu vulkanik,danbatu-batuan (Retnaningsih, 2013).

Abu vulkanik merupakan bahan material vulkanik yang disemburkan ke udara saat terjadinya suatu letusan, terdiri dari batuan berukuran besar sampai berukuran halus. Abu vulkanik yang halus dan berukuran sangat kecil, yaitu kurang dari 10 mikron, berpotensi mengganggu pernapasan, sedangkan abu vulkanik yang berukuran kurang dari 5 mikron dapat menembus saluran pernapasan bagian bawah atau organ paru-paru (Suryani, 2014). Abu vulkanik ini menimbulkan dampak yang sangat merugikan bagi kesehatan yaitu gangguan saluran pernafasan, iritasi terhadap mata, dan bagi kulit.

Di sistem pernafasan gejala-gejala kesehatan yang terjadi jika menghirup abu vulkanik adalah iritasi saluran pernapasan, sekresi dahak meningkat, iritasi dan radang pada tenggorokan, batuk kering, dada sakit, dan kesulitan bernapas. Letusan gunung sangat berpengaruh bagi kehidupan masyarakat yang ada di wilayah terkena letusan gunung, baik dari segi ekonomi, sosial dan kesehatan. Berdasarkan data BPS tanggal 06 Agustus 2016 menjelaskan terjadi aktivitas erupsi Gunung Dukono di Kabupaten Halmahera Utara, Maluku Utara dengan ketinggian abu vulkanik 
yang disemburkan Gunung Dukono mencapai 900 meter dengan paparan abu vulkanik sepanjang radius 2 kilometer dari puncak gunung. Data BNPB menyebutkan, daerah yang terdampak abu vulkanik, antara lain di Kecamatan Tobelo Utara yakni Desa Popilo 1.686 jiwa, Desa Popilo Utara 543 jiwa, Desa Kokotajaya 917 jiwa, Desa Ruko 889 jiwa dan Desa Luari 1.652 jiwa.

Bencana erupsi gunung merapi pernah terjadi pada tahun 2010 di Kota Magelang yang menyebabkan terdapatnya sekitar 42.671 jiwa yang mengungsi (Astuti et al, 2017). Hanya di kota Magelang dalam sejarah, diketahui bahwa Gunung Agung yang berada di Bali sempat meletus beberapa kali. Letusan pada tahun 1963 menyebabkan kerusakan material dengan korban jiwa sekitar 1.148 tewas dan 296 terluka (Hermawan.,2017).

Data BNPB menyebutkan bahwa erupsi Gunung Agung kembali terjadi pada tahun 2017 yang memberikan dampak di Kabupaten Karangasem, menurut Badan Penanggulangan Bencana Daerah (2017) terdapat 57.428 jiwa pengungsi di 357 titik yang tersebar di 9 kabupaten/kota di Bali. Berdasarkan hasil studi pendahuluan yang dilakukan di Puskesmas Kecamatan Rendang Karangasem pada tanggal 9 Juli 2019, dari data Puskesmas Kecamatan Rendang Karangasem pada bulan September 2016 sampai bulan Juni 2019 banyak terjadinya peningkatan penyakit ISPA pada setiap bulannya di wilayah Puskesmas Kecamatan Rendang Karangasem.

\section{METODE}

Penelitian ini menggunakan desain penelitian korelasional dengan pendekatan Cross sectional. Sampel sebanyak 90 minggu, karena kelengkapan data pada saat penelitian hanya tersedia dari bulan Juli 2018 minggu ke 2 sampai bulan Juni 2019 minggu ke 2 (45 minggu) dilibatkan dalam penelitian ini yang dipilih dengan teknik purposive sampling Peneliti datang ke puskesmas kecamatan rendang karangasem, peneliti memperkenalkan diri dan menjelaskan tujuan penelitian kepada ketua Puskesmas Kecamatan Rendang Karangasem, setelah ketua puskesmas setuju, selanjutnya peneliti meminta izin untuk meminta data penduduk yang terkena ISPA di Puskesmas Kecamatan Rendang Karangasem, Semua data sudah diberikan ke peneliti oleh pegawai Puskesmas Kecamatan Rendang Karangasem, data yang telah terkumpul diperiksa kelengkapannya dan kemudian dilakukan pengolahan data, setelah data terkumpul maka peneliti akan mencari perbandingan penduduk yang terkena ISPA pada saat sebelum terjadinya erupsi Gunung Agung dan sesudah terjadinya erupsi dan melakukan pengolahan data serta analisa data. Data dianalisa dengan analisis univariat dan bivariat menggunakan SPSS 20. Penelitian dilakukan selama 1 bulan yaitu pada bulan April tahun 2020 sampai Mei tahun 2020 di Puskesmas Kecamatan Rendang Karangasem.

\section{HASIL}

\section{Analisis Univariat}

Tabel 1

Distribusi frekuensi responden berdasarkan Umur

\begin{tabular}{ccc}
\hline Umur (th) & $\begin{array}{c}\text { Frekuensi } \\
(\mathrm{n})\end{array}$ & $\begin{array}{c}\text { Presntase } \\
(\%)\end{array}$ \\
\hline $1-10$ & 5 & 5,6 \\
\hline $11-20$ & 10 & 11,1 \\
$21-30$ & 20 & 22,2 \\
$31-40$ & 25 & 27,8 \\
$41-50$ & 30 & 33,3 \\
\hline Total & 90 & 100 \\
\hline
\end{tabular}

Berdasarkan Tabel 1 diatas dapat diketahui dari 90 responden, dapat dinformasikan lebih banyak berumur pada rentangan 41-50 tahun sebanyak 30 responden $(33,3 \%)$.

Tabel 2

Distribusi frekuensi responden berdasarkan jenis kelamin

\begin{tabular}{lcc}
\hline Jenis kelamin & Frekuensi (n) & $\begin{array}{l}\text { Prosentase } \\
(\%)\end{array}$ \\
\hline Laki-laki & 40 & 44,4 \\
\hline Perempuan & 50 & 55.6 \\
\hline Total & 90 & 100,0 \\
\hline
\end{tabular}

Berdasarkan Tabel 2 diatas dapat diketahui responden terbanyak berjenis kelamin perempuan sebanyak 50 responden $(55,6 \%)$.

Tabel 3

Distribusi frekuensi responden berdasarkan paparan letusan Gunung Agung

\begin{tabular}{lll}
\hline Paparan & $\begin{array}{l}\text { Frekuensi } \\
(\mathrm{n})\end{array}$ & $\begin{array}{l}\text { Prosenta } \\
\text { se }(\%)\end{array}$ \\
\hline Sebelum letusan & 45 & 50,0 \\
\hline Setelah letusan & 45 & 50,0 \\
\hline Total & 90 & 100,0
\end{tabular}

Berdasarkan Tabel 3 diatas dapat diketahui responden yang terlibat dalam penelitian ini sebanyak 45 data (50\%) sebelum terpapar letusan gunung agung dan sebanyak 45 data (50\%) setelah terpapar letusan Gunung Agung. 
Tabel 4

Statistik Deskriptif Kejadian ISPA

\begin{tabular}{lll}
\hline Statistik Deskriptif & $\begin{array}{c}\text { Sebelum } \\
\text { Letusan }\end{array}$ & $\begin{array}{c}\text { Setelah } \\
\text { Letusan }\end{array}$ \\
\hline Median & 2,00 & 5,00 \\
\hline Standar deviasi & 1,57 & 4,75 \\
\hline Minimum & 1,00 & 1,00 \\
Maksimum & 9,00 & 15,0 \\
\hline
\end{tabular}

Berdasarkan Tabel 4 dapat diketahui nilai ratarata kejadian ISPA sebelum terjadi letusan Gunung Agung sebesar 2,00 dan setelah letusan Gunung Agung sebesar 5,00.

\section{Analisa Bivariat \\ Hubungan Paparan Abu Vulkanik Letusan Gunung Agung Dengan Kejadian ISPA}

Nilai uji mann-Whitney sebesar 832,5 dan nilai $\mathrm{p}=$ 0,138 ( $\mathrm{P}>0,05)$, berarti Ha ditolak atau Ho diterima yang berarti tidak ada hubungan paparan abu vulkanik letusan Gunung Agung dengan kejadian ISPA di Puskesmas Kecamatan Rendang, Karangasem.

\section{PEMBAHASAN}

\section{Kejadian ISPA Sebelum Terjadi Letusan Gunung Agung}

Berdasarkan hasil penelitian yang menggunakan sebanyak 45 data pengamatan sebelum Gunung Agung meletus diketahui bahwa di wilayah Puskesmas Kecamatan Rendang Karangasem kejadian ISPA dengan rata-rata sebesar 5,68. Jumlah tertinggi sebanyak 15 orang dalam kurun waktu satu minggu, dan jumlah terendah sebanyak 1 orang dalam kurun waktu satu minggu.

Berdasarkan hasil penelitian pada saat setelah terjadinya letusan Gunung Agung, pasien ISPA yang ada di Puskesmas Kecamatan Rendang Karangasem meningkat dikarenakan pada saat terjadinya letusan Gunung Agung banyak masyarakat yang menghirup abu vulkanik saat terjadinya letusan.

Letusan Gunung Agung sangat berpengaruh bagi kehidupan manusia,baik dari segi financial, ekonomi, social dan kesehatan. Secara umum asap, abu dan gas yang yang dihasilkan oleh letusan Gunung Agung memberikan dampak negatif bagi kesehatan seperti iritasi mata, penyakit infeksi saluran pernapasan akut (ISPA), hingga gangguan pada kulit. Abu vulkanik yang halus dan berukuran sangat kecil, yaitu kurang dari 10 mikron, berpotensi mengganggu pernapasan, sedangkan debu vulkanik yang berukuran kurang dari 5 mikron dapat menembus saluran pernapasan bagian bawah atau organ paru-paru. Dampak kesehatan yang terjadi akibat debu vulkanik bisa bersifat akut maupun kronis. Berdasarkan penelitian, gejala pernapasan masyarakat yang ada di wilayah Puskesmas Kecamatan Rendang Karangasem maupun menghirup abu vulkanik adalah masyarakat merasakan sesak pada saat bernafas dan batuk kering saat menghirup abu vulkanik letusan Gunung Agung. Kondisi tersebut akan beresiko terhadap peningkatan kejadian Infeksi Saluran Pernapasan Akut (ISPA) pada masyarakat yang berada di kawasan Gunung Agung. Berdasarkan penelitian dapat diketahui responden yang terlibat dalam penelitian ini sebanyak 45 orang (50\%) sebelum terpapar letusan Gunung Agung dan sebanyak 45 orang $(50 \%)$ setelah terpapar letusan Gunung Agung. Berdasarkan penelitian masyarakat yang ada di wilayah Puskesmas Kecamatan Rendang Karangasem masih terpapar abu vulkanik letusan Gunung Agung dikarenakan Gunung Agung tidak meletus sekali saja melainkan berkali kali yang menyemburkan abu vulkanik sedikit demi sedikit. Dari data yang diperoleh, peningkatan jumlah ISPA setelah terjadi letusan Gunung Agung pada masyarakat yang berada di wilayah Puskesmas Rendang Karangasem, disebabkan oleh debu halus akibat polusi udara yang berasal dari letusan Gunung Agung.

Hasil penelitian ini sejalan dengan penelitian Umar et al. (2017) tentang hubungan antara paparan abu vulkanik letusan gunung Dukono dengan kejadian ISPA pada wanita (40-60 th) didesa Popilo kecamatan Tobelo Halmahera Utara dengan sampel penelitian sebanyak 63 Wanita (40-60 tahun) yang menunjukan hasil presentase $100 \%$ terpapar abu vulkanik dan mengalami ISPA. Serta hasil penelitian ini juga sejalan dengan penelitian (Crhisanti, 2015) tentang Hubungan Paparan Debu Vulkanik Dari Lahar Dingin Gunung Merapi Dengan Kejadian ISPA Pada Balita di kecamatan Salam, Magelang yang menunjukan hasil bahwa terdapat hubungan yang signifikan antara paparan abu vulkanik dengan kejadian ISPA dengan nilai $\mathrm{p}$ value 0,041 ( $\mathrm{p}$ value $<0,05$ ).

\section{Kejadian ISPA Setelah Terjadi Letusan Gunung Agung}

Berdasarkan hasil penelitian yang menggunakan sebanyak 45 data pengamatan sebelum Gunung Agung meletus diketahui bahwa di wilayah Puskesmas Kecamatan Rendang Karangasem kejadian ISPA dengan rata-rata sebesar 5,68. Jumlah tertinggi sebanyak 15 orang dalam kurun waktu satu minggu, dan jumlah terendah sebanyak 1 orang dalam kurun waktu satu minggu.

Berdasarkan hasil penelitian pada saat setelah terjadinya letusan Gunung Agung, pasien ISPA yang ada di Puskesmas Kecamatan Rendang Karangasem meningkat dikarenakan pada saat terjadinya letusan Gunung Agung banyak masyarakat yang menghirup abu vulkanik saat terjadinya letusan. Letusan Gunung Agung sangat berpengaruh bagi kehidupan manusia,baik dari segi financial, ekonomi, social dan 
kesehatan. Secara umum asap, abu dan gas yang yang dihasilkan oleh letusan Gunung Agung memberikan dampak negatif bagi kesehatan seperti iritasi mata, penyakit infeksi saluran pernapasan akut (ISPA), hingga gangguan pada kulit. Abu vulkanik yang halus dan berukuran sangat kecil, yaitu kurang dari 10 mikron, berpotensi mengganggu pernapasan,sedangkan debu vulkanik yang berukuran kurang dari 5 mikron dapat menembus saluran pernapasan bagian bawah atau organ paru-paru. Dampak kesehatan yang terjadi akibat debu vulkanik bisa bersifat akut maupun kronis. Berdasarkan penelitian, gejala pernapasan masyarakat yang ada di wilayah Puskesmas Kecamatan Rendang Karangasem maupun menghirup abu vulkanik adalah masyarakat merasakan sesak pada saat bernafas dan batuk kering saat menghirup abu vulkanik letusan Gunung Agung. Kondisi tersebut akan beresiko terhadap peningkatan kejadian Infeksi Saluran Pernapasan Akut (ISPA) pada masyarakat yang berada di kawasan GunungAgung.

Berdasarkan penelitian dapat diketahui responden yang terlibat dalam penelitian ini sebanyak 45 orang $(50 \%)$ sebelum terpapar letusan Gunung Agung dan sebanyak 45 orang (50\%) setelah terpapar letusan Gunung Agung. Berdasarkan penelitian masyarakat yang ada di wilayah Puskesmas Kecamatan Rendang Karangasem masih terpapar abu vulkanik letusan Gunung Agung dikarenakan Gunung Agung tidak meletus sekali saja melainkan berkali kali yang menyemburkan abu vulkanik sedikit demi sedikit. Dari data yang diperoleh, peningkatan jumlah ISPA setelah terjadi letusan Gunung Agung pada masyarakat yang berada di wilayah Puskesmas Rendang Karangasem, disebabkan oleh debu halus akibat polusi udara yang berasal dari letusan Gunung Agung.

Hasil penelitian ini sejalan dengan penelitian Umar et al. (2017) tentang hubungan antara paparan abu vulkanik letusan gunung Dukono dengan kejadian ISPA pada wanita (40-60 th) didesa Popilo kecamatan Tobelo Halmahera Utara dengan sampel penelitian sebanyak 63 Wanita (40-60 tahun) yang menunjukan hasil presentase $100 \%$ terpapar abu vulkanik dan mengalami ISPA. Serta hasil penelitian ini juga sejalan dengan penelitian (Crhisanti, 2015) tentang Hubungan Paparan Debu Vulkanik Dari Lahar Dingin Gunung Merapi Dengan Kejadian ISPA Pada Balita di kecamatan Salam, Magelang yang menunjukan hasil bahwa terdapat hubungan yang signifikan antara paparan abu vulkanik dengan kejadian ISPA dengan nilai $\mathrm{p}$ value 0,041 ( $\mathrm{p}$ value $<0,05$ ).

\section{Hubungan Paparan Abu Vulkanik Letusan Gunung Agung Dengan Kejadian ISPA}

Proses penghitungan uji Mann-Whitne diawali dengan dua kelompok data yang berbeda dari segi waktu kejadiannya, dalam hal ini data yang dibandingkan adalah kejadian ISPA sebelum Gunung Agung meletus dan kejadian ISPA pasca Gunung
Agung Meletus. Kemudian data diolah menggunakan SPSS masuk pada menu analyze, non parametic test kemudian diolah menggunakan instruksi uji MannWhitney. Berdasarkan nilai uji Mann-Whitney sebesar 832,5dan nilai $\mathrm{p}=0,138(\mathrm{P}>0,05)$, berarti Ha ditolak atau Ho diterima yang berarti tidak ada hubungan paparan abu vulkanik letusan Gunung Agung dengan kejadian ISPA di Puskesmas Kecamatan Rendang, Karangasem.

Dari hasil penelitian sebelum terjadinya letusan Gunung Agung penyakit ISPA di wilayah Puskemas Kecamatan Rendang Karangasem dapat disebabkan karena faktor alergi, debu, bakteri, sanitasi rumah yang kurang bagus, pencemaran udara dan asap rokok.

Hasil penelitian ini sejalan dengan penelitian (Milo et al., 2012) tentang hubungan kebiasaan merokok di dalam rumah dengan kejadian ispa pada anak umur 1-5 tahun di puskesmas sario kota manado yang menunjukan hasil bahwa terdapat hubungan yang signifikan kebiasaan merokok di dalam rumah terhadap kejadian ispa dengan nilai $\mathrm{p}$ value 0,002 (p value $<0,05$ ) dan penelitian setelah terjadinya letusan Gunung Agung penyakit ISPA disebabkan oleh debu halus akibat polusi udara yang berasal dari letusan Gunung Agung hasil penelitian ini sejalan dengan penelitian (Crhisanti, 2015) tentang Hubungan Paparan Debu Vulkanik Dari Lahar Dingin Gunung Merapi Dengan Kejadian ISPA Pada Balita di kecamatan Salam, Magelang yang menunjukan hasil bahwa terdapat hubungan yang signifikan antara paparan abu vulkanik dengan kejadian ISPA dengan nilai $\mathrm{p}$ value 0,041 ( $\mathrm{p}$ value $<0,05$ ).

Temuan dalam penelitian ini tidak bersesuaian dengan penelitan sebelumnya seperti yang dilakukan oleh Thaib et al. (2015) pada penelitian menggunakan uji statistik uji chi square menunjukkan bahwa hasil $\mathrm{p}$ $=0,006(<0,05)$ ini berarti terdapat hubungan antara paparan debu dengan kejadian gangguan saluran pernafasaan di Kelurahan Kairagi Satu Lingkungan 3 Kota Manado. Dan berdasarkan penelitian Umar et al. (2017), pada penelitian ini menggunakan uji spearmen rank dengan hasil $\mathrm{p}=0,002(<0,05)$ ini berarti terdapat hubungan antara paparan abu vulkanik letusan gunung Dukono dengan kejadian ISPA pada wanita (40-60 th) didesa Popilo kecamatan Tobelo Halmahera Utara.

Berdasarkan hasil penelitian, temuan dalam penelitian ini tidak ada perbedaan yang signifikan kejadian ISPA sebelum dan sesudah letusan Gunung Agung, Puskesmas Kecamatan Rendang Karangasem sendiri sudah memberikan sosialiasi ke wilayah kerja Puskesmas Kecamatan Rendang Karangasem serta Puskesmas Kecamatan Rendang Karangasem juga sudah memberikan himbauan pada masyarakat untuk menggunakan masker agar terhindar dari abu vulkanik letusan Gunung Agung serta memberikan penanganan yang sigap dan cepat kepada masyarakat yang terkena ISPA sesuai dengan SOP penanganan pasien ISPA di Puskesmas Kecamatan Rendang Karangasem, 
keaktifan aparat BNPB yang intens membantu masyarakat dalam bencana letusan Gunung Agung, telah dilakukan tindakan pengungsian pada seluruh masyarakat yang tinggal di wilayah dekat Gunung Agung, dan ketersediaan posko kesehatan pasca bencana letusan Gunung Agung dan juga ketersediaan bantuan seperti sembako untuk para pengungsi bencana letusan Gunung Agung dan juga relawan serta pemerintah selalu membantu dan merawat masyarakat agar tetap sehat, serta semangat di pengungsian yang tersebar dibeberapa wilayah.

Hasil penelitian ini didukung oleh teori yang dinyatakan oleh Nurjanah (2013:19), bahwa menurunkan kerentanan dan meningkatkan kemampuan, sehingga resiko terhadap masyarakat menjadi berkurang. Hal ini bertujuan untuk mengurangi terjadinya kerentanan dan meningkatkan kapasitas akibat terjadinya bencana alam di suatu wilayah. Mengurangi kerentanan ini bertujuan untuk memperkecil bahaya dan BNPB membantu masyarakat lebih sigap dan tanggap jika akan terjadi suatu bencana dan juga mampu mengurangi dan mencegah terjadinya korban jiwa.

Hasil penelitian ini sejalan dengan penelitian (Rofifah, 2019) tentang hubungan antara pengetahuan dengan kesiapsiagaan bencana pada mahasiswa keperawatan Universitas Diponegoro yang menunjukan hasil bahwa terdapat hubungan yang signifikan antara kedua variabel dengan nilai $\mathrm{p}$ value $0,000(\mathrm{p}$ value $=0,05)$.

\section{KESIMPULAN}

Berdasarkan hasil penelitian tentang hubungan paparan abu vulkannik letusan Gunung Agung dengan kejadian ISPA di Puskesmas Kecamatan Rendang, Karangasem yaitu rata-rata kejadian ISPA sebelum terjadi letusan Gunung Agung yaitu 2,0 per minggu, rata-rata kejadian ISPA setelah terjadi letusan Gunung Agung yaitu 5,0 per minggu, dan tidak ada hubungan paparan abu vulkannik letusan Gunung Agung dengan kejadian ISPA di Puskesmas Rendang, Karangasem.

\section{DAFTAR PUSTAKA}

1. Arif, S., \& Herwanti, B. (2015). Faktor - Faktor Yang Berhubungan Dengan Kejadian Ispa Pada Anak Umur 6-59 Bulan Di Nusa Tenggara Timur (Analisa Data Sekunder Riskesdas 2007). Nutrire Diaita, 7(2), 81-90.

2. Astuti, cindi. (2017). hubungan perilaku keluarga dengan kejadian ispa pada balita di desa citaji kecamatan cimanggu kabupaten cilacap. Skripsi, 1-15.

3. Astuti, D., Candra, A., \& Fitranti, D. Y. (2019). Pengaruh Suplementasi Zat Besi Dan Seng Terhadap Frekuensi ISPA Pada Anak Usia 2-5
Tahun. Media Gizi Mikro Indonesia, 10(2), 7790. https://doi.org/10.22435/mgmi.v10i2.1365

4. Depkes RI. (2012). Modul Tatalaksana Standar Pneumonia. In Pneumonia Balita. Retrieved from https://www.scribd.com/upload-document.

5. Hartini retnaningsih. (2013). Letusan Gunung Penanganan Bencana. Info Singkat Kesejahteraan Sosial, V(September), 9-12.

6. Maharani, F. M. (2017). Pengaruh Destination Image Terhadap Destination Loyalty Pada Kabupaten Malang Menurut Wisatawan Asal Surabaya. Jurnal Ilmiah Mahasiswa Universitas Surabaya, 6(1), 630-640. https://doi.org/10.1007/978-3-030-24436-1_17

7. Nursalam. (2011). Manajemen Keperawatan: Aplikasi dalam Praktik Jakarta: Salemba Medika.

8. Nursalam. (2013a). Konsep Penerapan Metode Penelitian Ilmu Keperawatan. Jakarta: Salemba Medika.

9. Nursalam. (2013b). Metedologi Penelitian Illmu Keperawatan (4th ed.). Jakarta: Selemba Medika.

10. Pangaribuan, S. (2017). Hubungan Kondisi Lingkungan Rumah dengan Kejadian ISPA pada Balita di Puskesmas Remu Kota Sorong. Global Health Science, 2(1), 6-10.

11. Putra, Y., \& Wulandari, S. S. (2019). Faktor Penyebab Kejadian ISPA. Jurnal Kesehatan, 10(1), 37. https://doi.org/10.35730/jk.v10i1.378

12. Sugiyono. (2010a). Metode Penelitian Bisnis (1st ed.). Bandung: Alfabeta.

13. Sugiyono. (2010b). Metode Penelitian Kuantitatif Kualitatif Dan R\&D. Bandung: Alfabeta.

14. Suryani, A. S. (2014). Dampak negatif abu vulkanik terhadap lingkungan dan kesehatan. P3DI Setjen DPR RI, VI(4), 9-12. Retrieved from berkas.dpr.go.id/.../Info Singkat-VI-4-IIP3DI-Februari-2014-67.pdf

15. Thaib, Y., Lampus, B., \& Akili, R. (2015). Hubungan Antara Paparan Debu Dengan Kejadian Gangguan Saluran Pernafasaan Pada Masyarakat Kelurahan Kairagi Satu Lingkungan 3 Kota Manado. Jurnal Administrasi Publik UNSRAT, 4(32), 1448.

16. Umar, S., Sutriningsih, A., \& Warsono. (2017). Hubungan antara paparan abu vulkanik letusan Gunung Dukono dengan kejadian ISPA pada wanita (40-60 tahun) di Desa Popilo Kecamatan Tobelo Halmahera Utara. Nursing News, 2(3), 112-121. 
Jurnal Ilmiah Pannmed (Pharmacyst, Analyst, Nurse, Nutrition, Midwivery, Environment, Dental Hygiene)

Vol. 15 No. 3 September - Desember 2020

17. Widoyono. (2008). Infeksi Saluran Pernapasan Akut (ISPA). Penyakit Tropis Epidemiologi,
Penularan, Pencegahan Dan Pemberantasan, $155-160$. 